\title{
Betonarme Yapıda Perde Yeri Seçiminin Yapısal Davranışa Etkisinin TBDY 2018 ve DBYBHY 2007 Yönetmeliklerine Göre Karşılaştırılması
}

\author{
${ }^{1}$ Gülnur BURNAZOĞLU $\quad{ }^{* 2}$ Necati MERT $\quad{ }^{* 3}$ Hüseyin KASAP \\ ${ }^{1}$ SAÜ: Fen Bilimleri Enstitüsü, Sakarya, TURKEY \\ *2,3SAÜ Mühendislik Fakültesi, İnşaat Mühendisliği Bölümü ,Sakarya, Turkey
}

\begin{abstract}
Özet
Son yıllarda birçok sebebe bağlı olarak büyük şehirlere olan göçler oldukça yüksek seviyelere ulaşmıştır. Nüfustaki bu artış, istihdam, barınma ve iş sahası açısından yüksek katlı yapı yapma ihtiyacını doğurmuştur. Bu ihtiyaç karşısında geliş̧en teknolojiyle birlikte yüksek katlı binaların önemi artmıştır. Günümüzde yüksek katlı yapılara olan ihtiyaç ve artan ilgi, taşıyıcı sistemlerde perdenin önemini arttırmıştır. Perdeli sistemler, yapı taşıyıcı sisteminde tek başlarına kullanılabildikleri gibi, çerçevelerle birlikte de kullanılabilmektedir. Perde çerçeve karşılıklı etkileşimiyle yapıya kazandırılan dayanım ve süneklikten dolayı daha çok tercih edilmektedir.

Bu çalışmada konut amaçlı kullanılacak 5 katlı ve 11 katlı iki farklı yapı için, perde yerleşim düzenleri değiştirilerek hazırlanan yapı modellerinde oluşan yapısal davranışlar incelenmiştir. Beton kalitesi, kat alanı ve zemin sınıfı sabit tutulan yapılarda, çerçeveli sistem, referans sistem olarak kabul edilmiştir. Referans plan üzerine, eşit miktarda ve aynı ebatlarda perdeler eklenmiştir. Perde en kesit alanı sabit tutulup, referans plan üzerinde perde yerleşim düzenleri değiştirilerek 6 farklı sistem türü oluşturulmuş̧ur.

Yapılan çözümleme sonucunda sistemlerin göreli kat ötelemeleri, kat deplasmanları, yapı periyotları, tabanda meydana gelen kesme kuvveti, perde kesme kuvvetinin toplam taban kesme kuvvetine oran1, A1 burulma düzensizliği, B1 zayıf kat düzensizliği ve B2 yumuşak kat düzensizliği sonuçları incelenmiştir. Sonuçlar birbirleriyle karşılaştırılarak taşıyıcı sistemlerin farklılıklarının yapı davranışını ne oranda etkilediği araştırılmıştır.
\end{abstract}

\begin{abstract}
In recent years, migration to large cities has reached very high levels due to several reasons. This increase in population has created the need for high-rise building in terms of employment, housing and job site. In the face of this need, the importance of high-rise buildings increased with the developing technology.

Nowadays, the need and increased interest in high-rise buildings has increased the importance of the shear walls in the carrier systems. The shear walls systems can be used alone in the structure carrier system as well as with the frames. The shear walls- frame is more preferred due to its strength and ductility.

In this study, the structural behaviors of two different 5 storey and 11 storey building will be investigated. In buildings with constant concrete quality, floor area and floor class, the framed system is accepted as the reference system. On the reference plan, curtains of equal quantity and the same dimensions were added. 6 different system types were created by keeping the cross section area of the wall constant and changing the wall layout patterns on the reference plan.

As a result of the analysis, relative floor displacements of the systems, floor displacements, construction periods, the shear force at the base, the ratio of the shear walls shear force to the total base shear force, A1 torsional irregularity, B1 weak layer irregularity and B2 soft floor irregularity results were examined. By comparing the results with each other, it has been investigated how the differences of carrier systems affect the structural behavior.
\end{abstract}

Key words: Shear walls, structural system, displacements, irregularity, shear force

\footnotetext{
* Corresponding author: Address: Faculty of Engineering, Department of Civil Engineering Sakarya University, 54187, Sakarya TURKEY. E-mail address: mert@ sakarya.edu.tr, Phone: +902642955743
} 


\section{Giriş}

Türkiye, dünyanın aktif deprem kuşaklarından biri olan Alp Himalaya deprem kuşağı üzerinde olup deprem riski oluşturabilecek yüzlerce aktif fay hattı üzerinde bulunmaktadır. Sismik etkiler açısından bu kadar tehlikeli bir coğrafyada yer almak, üzerine inşa edilecek yapılarda hata oranını teknik açıdan en aza indirgememiz ve iyi analizler yapmamız gerektiğini göstermektedir. Son yıllarda büyük şehirlere yaşanan önemli göçler sonucunda nüfusun kontrolsüz artması alt ve üst yapıların önemini arttırmıştır. Nüfustaki bu artış, istihdam, barınma ve iş sahası açısından yüksek katlı yapı yapma ihtiyacını doğurmuştur. Yapılan her yüksek katlı yapı, estetik ve ekonomik açıdan beklentileri aynı anda karşılamak durumundadır. Fakat tasarımda göz önüne alınan bu iki faktörden daha önemli olan özelliği ise yüksek katlı yapıların güvenliğidir. Bunun için doğru malzeme ve taşıyıcı sistem seçimi oldukça önemlidir.

Betonarme perdeler büyük eğilme rijitlikleri ve kesme alanları nedenleriyle yapıya etkiyen yatay yükün bir bölümünü karşılarlar. Ayrıca yatay yükler altında kat yer değiştirmelerinin ve ikinci mertebe momentlerin sinırlandırılması bakımından bazı durumlarda perdelerin kullanılması zorunlu olur.

Perdeler çerçevelerle birlikte kullanıldığında daha sünek bir sistem elde edilir. Şekil 1'de görüldüğü gibi perdenin şekil değiştirmesinde eğilme momenti etkili olur ve katlar arasi en büyük yerdeğiştirme üst katlarda meydana gelirken, çerçevede ise yatay ötelemeler kat rijitliğine bağlı olarak kesme kuvvetinin en büyük olduğu alt katlarda meydana gelmekte ve üst katlara doğru azalmaktadir[1]

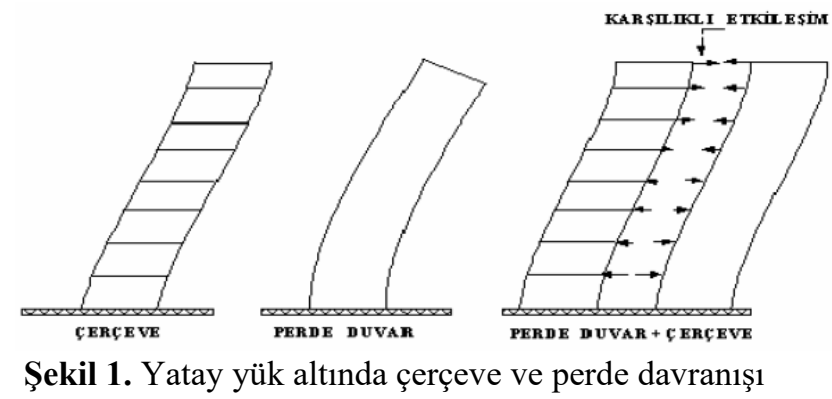

\section{Problem Tanıtımı ve Analizi}

Bu çalışmada, kullanım amacı konut olarak seçilen 5 katlı ve 11 katlı iki farklı yapı için, kat planında perde yerleşim düzenleri değiştirilerek hazırlanan modellerde meydana gelecek yapısal davranışlar incelenmiştir.

Beton kalitesi, kat alanı ve zemin sınıfı sabit tutulan 5 katlı yapıda, çerçeveli sistem, referans sistem olarak kabul edilmiştir. Referans plan üzerine, toplam da 10 adet 30x530 ebatlarında perdeler eklenmiştir. Perde en kesit alanı sabit tutulup, referans plan üzerinde perde yerleşim düzenleri değiştirilerek 6 farklı sistem türü oluşturulmuştur. Toplamda oluşan 7 sistem DBHBHY 2007 ve TBDY 2018'e göre ayrı ayrı ideCAD Statik IDS v10.05 bilgisayar programında çözülmüştür. Beton kalitesi, kat alanı ve zemin sınıfı sabit tutulan 11 katlı yapıda, çerçeveli sistem, referans sistem olarak kabul edilmiştir. Referans plan üzerine, toplam da 8 adet 40x600 ebatlarında perdeler eklenmiştir. Perde en kesit alanı sabit tutulup, referans plan üzerinde perde yerleşim düzenleri değiştirilerek 6 farklı sistem türü oluşturulmuştur. Toplamda oluşan 7 sistem TBDY 2018'e göre 
ideCAD Statik IDS v10.05 ve SAP2000 bilgisayar programlarıyla ayrı ayrı çözülmüştür. Bu çözümleme sonucunda sistemlerin göreli kat ötelemeleri, kat deplasmanları, yapı periyotları, tabanda meydana gelen kesme kuvveti, perde kesme kuvvetinin toplam taban kesme kuvvetine oranı, A1 burulma düzensizliği, B1 zayıf kat düzensizliği ve B2 yumuşak kat düzensizliği sonuçları incelenmiştir. Tüm sistemlerin sonuçları kendi içinde birbirleriyle karşılaştırılarak taşıyıcı sistemlerin farklılıklarının yapı davranışını ne oranda etkilediği araştırılmıştır.

Sistemler, DBYBHY-2007' ye göre analiz edilirken Yap1 I. Derece deprem bölgesinde olup Etkin Yer İvmesi Katsayısı Ao=0.40 alınmıştır. Bina önem katsayısı I=1.0 alınmıştır.Yerel zemin sınıfı Z4 kabul edildiği için spektrum karakteristik periyotlar DBYBHY 2007 Tablo 2.4' den $T_{A}=0.20$ ve $T_{B}=0.90$ alınmıştır. Spektrum katsayısı, $T_{A}, T_{B}$ ve bina doğal periyodu T'ye bağlı olarak, DBYBHY 2007'de Denklem 2.2' ye göre hesaplanacaktır.

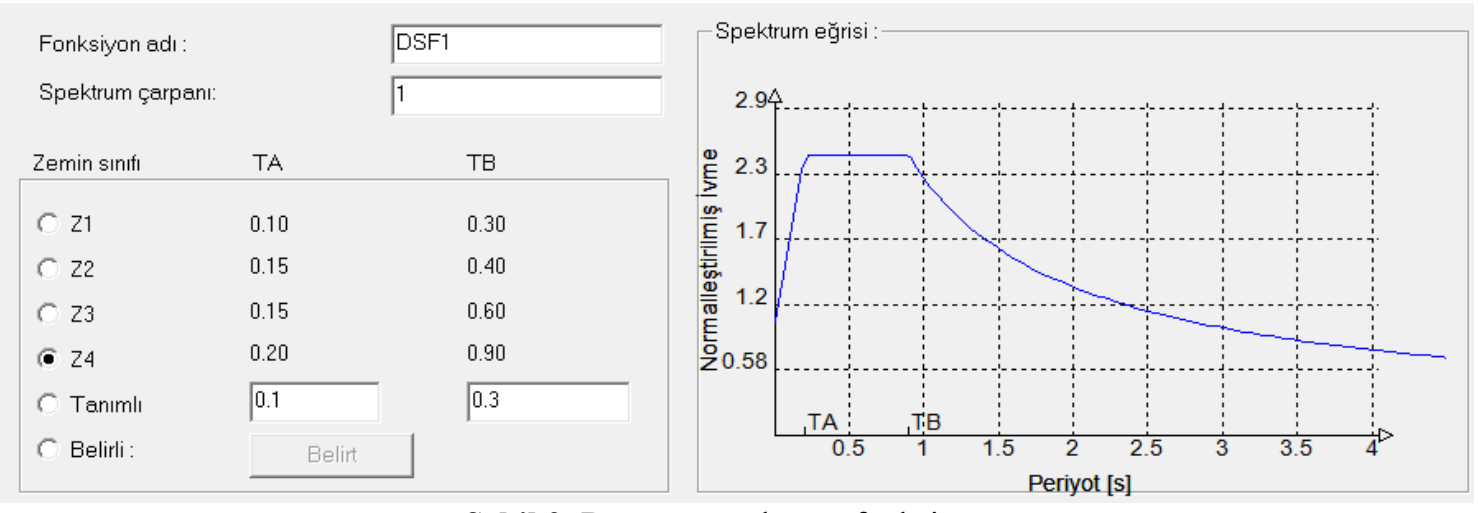

Şekil 2. Davranış spektrum fonksiyonu

Sistemler TBDY-2018'e göre analiz edilirken, Yapı Adapazarı bölgesinde yer aldığı için deprem yer hareketleri düzeyi-2 (DD-2) dir. Yapı kullanım sınıfı BKS=3 olduğu için bina önem katsayısı I=1.0 alınmıştır. Deprem yer hareketleri spektrumu; harita spektral ivme katsayıları ve tasarım spektral ivme katsayılarına bağlıdır. Harita spektral ivme katsayıları, Türkiye Deprem Tehlike Haritaları kapsamında $S_{S}$ ve $S_{1}$ değerleri, yerel zemin etki katsayılarıyla $\left(F_{S}\right.$ ve $\left.F_{1}\right)$ çarpılarak tasarım spektral ivme katsayılarına $\left(S_{D S}\right.$ ve $\left.S_{D 1}\right)$ dönüşür. Yerel zemin sınıfı ZE için; $S_{S}=1,465$ için $F_{S}=0,814$ (TBDY 2018, Tablo 2.1) ve $S_{1}=0,403$ için $F_{1}=2,394$ (TBDY 2018, Tablo 2.2) alınmıştır.
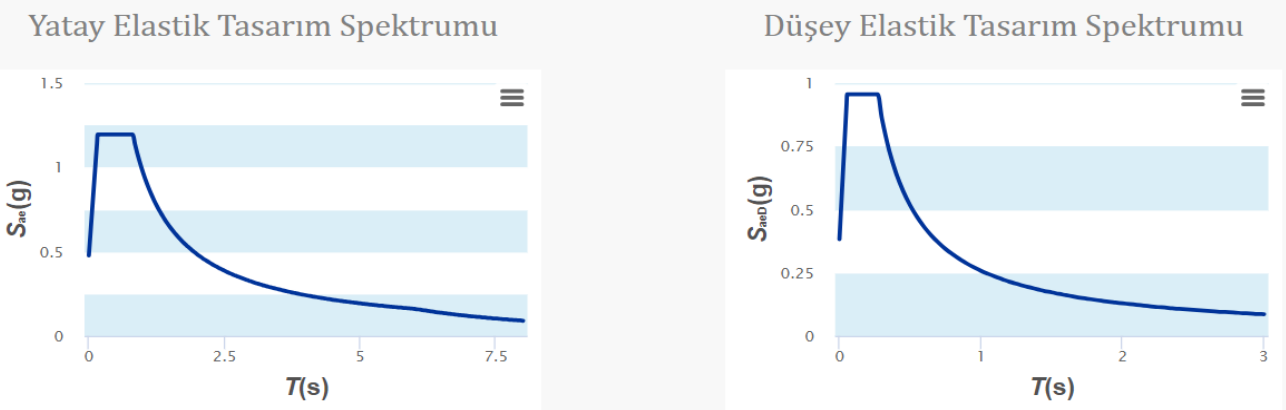

Şekil 3. TBDY 2018 için Yatay ve düşey tasarım spektrum eğrileri 
Bina tasarım sınıfı $0.75 \leq S_{D S}$ ve $\mathrm{BKS}=3$ olduğu için DTS=1 alınmıştır. Yapılarda süneklik düzeyi yüksektir. Dayanım Fazlalığı Katsayısı D ve Taşıyıcı Sistem Davranış Katsayısı R, çerçeveli veya çerçeveli-perdeli sistemlere göre TBDY 2018'de Tablo 4.1' den seçilmiştir.

Modal çözümleme sırasında, $\mathrm{X}$ ve $\mathrm{Y}$ deprem doğrultularından her bir mod için hesaplanan taban kesme kuvveti modal etkin kütlelerinin toplamının, hiçbir zaman bina toplam kütlesinin \%95' inden daha az olmaması kuralına göre mod birleştirme hesabında dikkate alınmıştır.

\subsection{Katlı Betonarme Yapı Modelleri}

Yapılan tasarımlarda kat yükseklikleri zemin kat 4 m, diğer katlar 3 m, aks açıklıkları 5 metredir. Kolonlar dikdörtgen kesit olup 40x60 cm, kirişler 30x50 cm, döşeme kalınlığ $15 \mathrm{~cm}$, perdeler 30x530 olarak tasarlanmıştır. Yapılan bütün planlarda aks sayısı, aks açıklıkları ve planlardaki toplam perde alanı sabittir. Planda perde yerleri değiştirilerek oluşan 7 farklı yapı incelenmiştir. Hazırlanan yapı modelleri aşağıdaki gibidir.

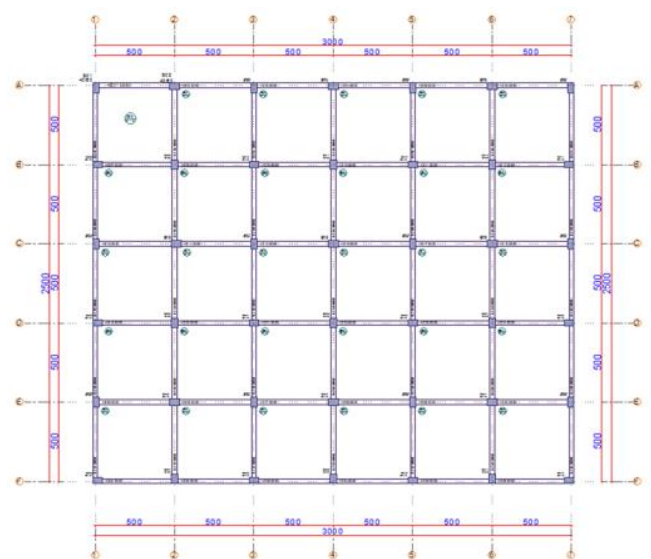

Sistem 1. Referans Model

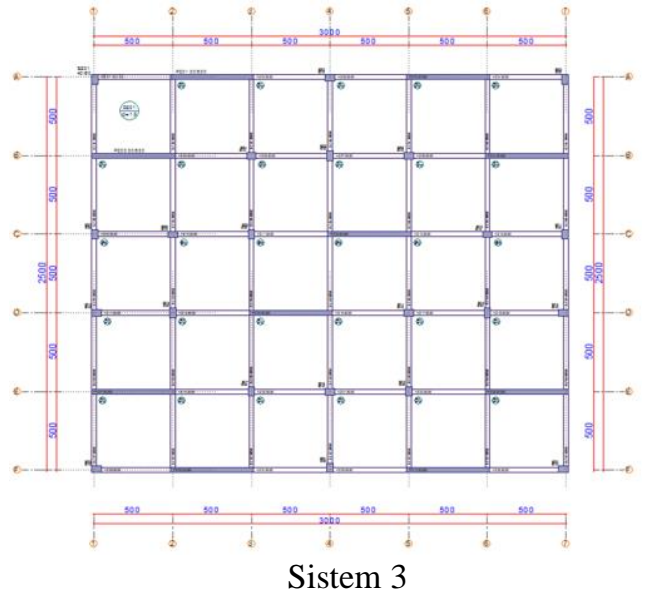

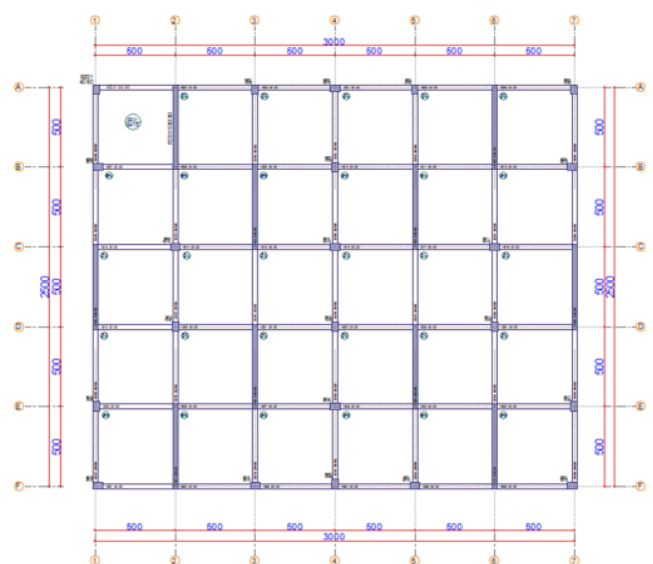

Sistem 2

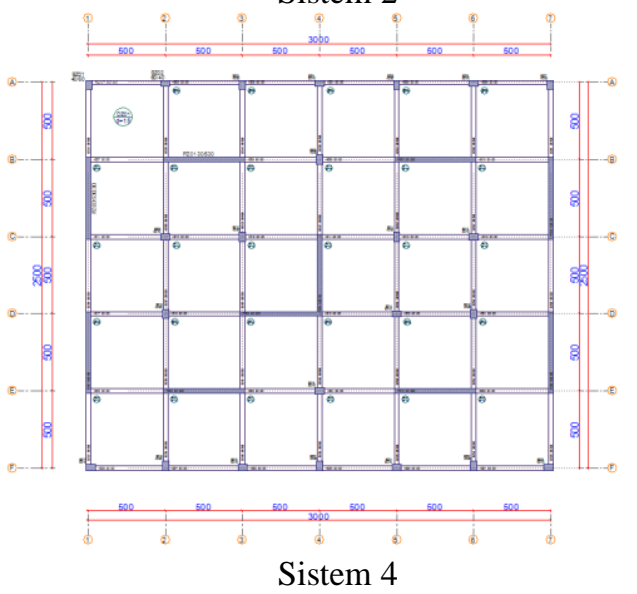



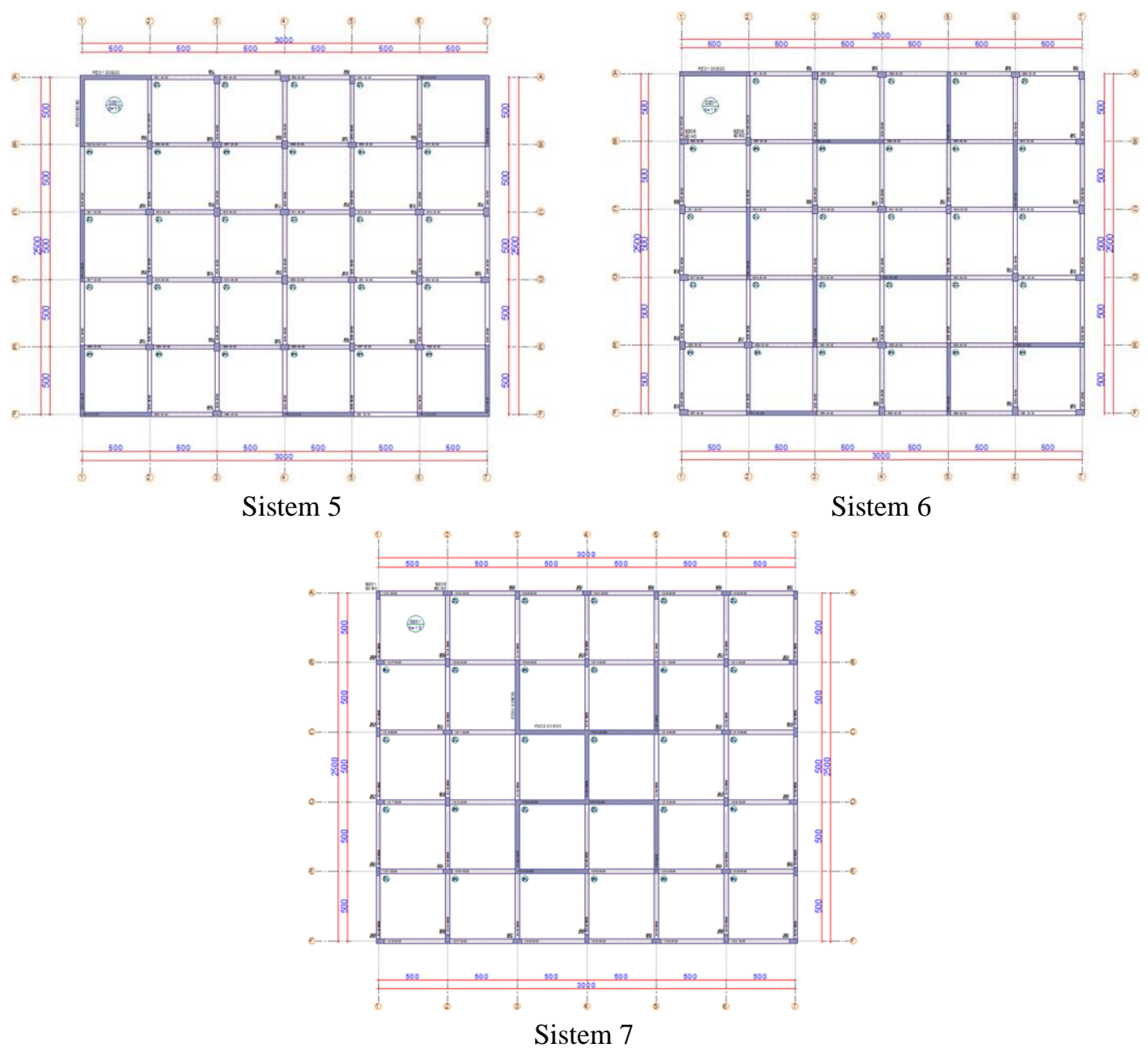

Şekil 4. Analiz için hazırlanan 5 katlı betonarme yapıların perdeli-çerçeveli taşıyıcı sistem modelleri

Tüm modellerde C25 beton sınıfı ve S 420 donatı çeliği kullanılmıştır. Planlanan yapı 5 katlı olup $(30,30 \times 25,30 \mathrm{~m}) 766,59 \mathrm{~m}^{2}$ kat alanına sahiptir.

Sistem 1, referans plan olarak belirlenen ve taşıyıcı sistemi çerçeve olan sistemdir. Perde elemanı içermemektedir.

Sistem 2 için düşey taşıyıcı olan kolonlara ek olarak, sadece $\boldsymbol{Y}$ doğrultusuna 10 adet $30 \times 530 \mathrm{~cm}$ ebatlarında simetrik olarak perdeler eklenmiştir.

Sistem 3 için düşey taşıyıcı olan kolonlara ek olarak, sadece $\boldsymbol{X}$ doğrultusuna 10 adet 30x530 cm ebatlarında simetrik perdeler yerleştirilmiş̧ir.

Sistem 4 için düşey taşıyıcı olan kolonlara ek olarak, 5 adet $X$ yönünde ve 5 adet $Y$ yönünde olmak üzere toplamda 10 adet $30 \times 530 \mathrm{~cm}$ uzunluğunda perde eklenmiştir.

Sistem 5 için düşey taşıyıcı olan kolonlara ek olarak özellikle yapının burulmasını sınırlandırmak amaciyla 4 köşede ve diş çevrede toplam 10 adet $30 \times 530 \mathrm{~cm}$ uzunluğunda perdeler teşkil edilmiştir. Sistem 6 için düşey taşıyıcı olan kolonlara ek olarak 5 adet $X$ yönünde ve 5 adet $Y$ yönünde olmak üzere asimetrik olarak toplamda 10 adet $30 \times 530 \mathrm{~cm}$ uzunluğunda perde eklenmiştir.

Sistem 7 için düş̧ey taşıyıcı olan kolonlara ek olarak 5 adet $X$ yönünde ve 5 adet $Y$ yönünde olmak üzere binanın çekirdek bölgesinde toplamda 10 adet 30x530cm uzunluğunda perde eklenmiştir. 


\subsection{Katlı Betonarme Yapı Modelleri}

Yapılan tasarımlarda kat yükseklikleri zemin kat 4 m, diğer katlar 3 m, aks açıklıkları 5,5 metredir. Kolonlar, dış çerçevede dikdörtgen kesit olup 50*100 cm, orta bölgede kare 80*80, kirişler 30*60 $\mathrm{cm}$, döşeme kalınlığ1 $15 \mathrm{~cm}$, perdeler 40x600 olarak tasarlanmıştır. Yapılan bütün planlarda aks sayısı, aks açıklıkları ve planlardaki toplam perde alanı sabittir. Planda perde yerleri değiştirilerek oluşan 7 farklı yapı incelenmiştir. Hazırlanan yapı modelleri aşağıdaki gibidir.

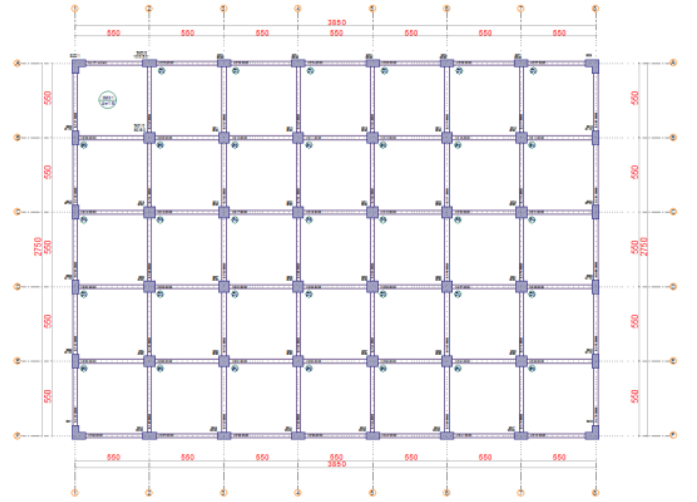

Sistem 1. Referans Model

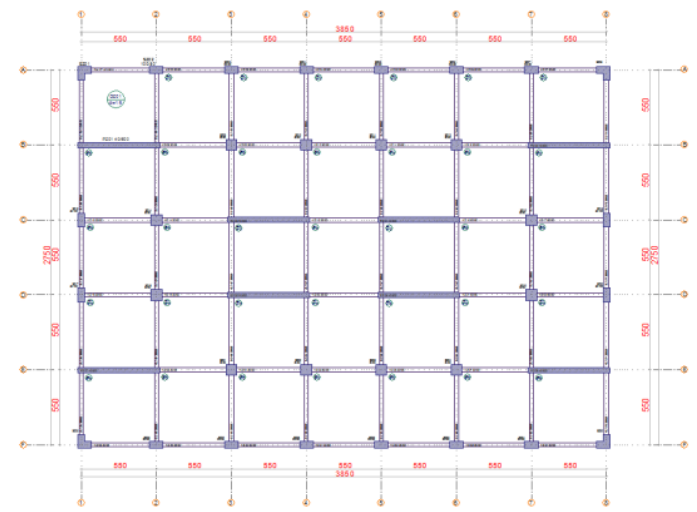

Sistem 3

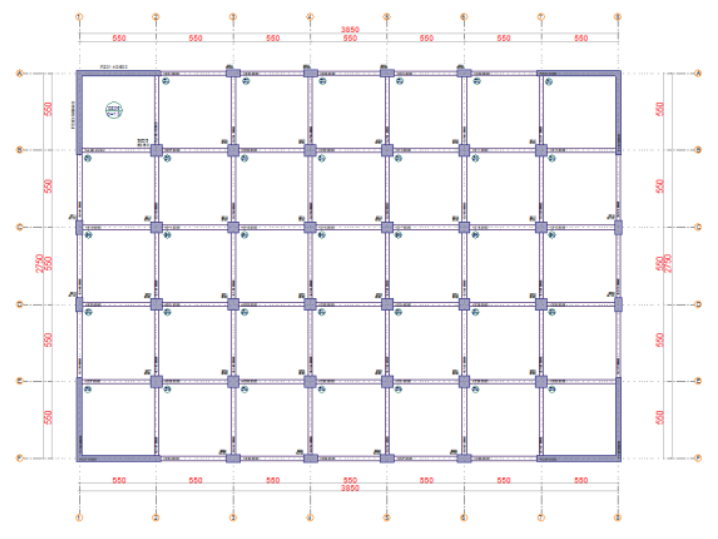

Sistem 5

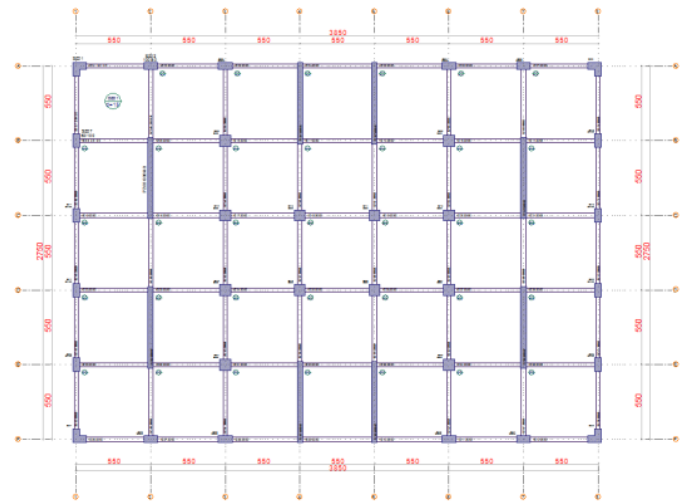

Sistem 2

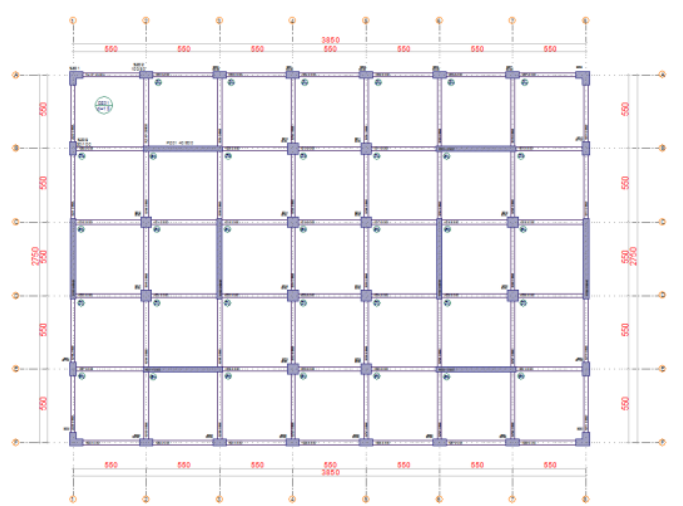

Sistem 4

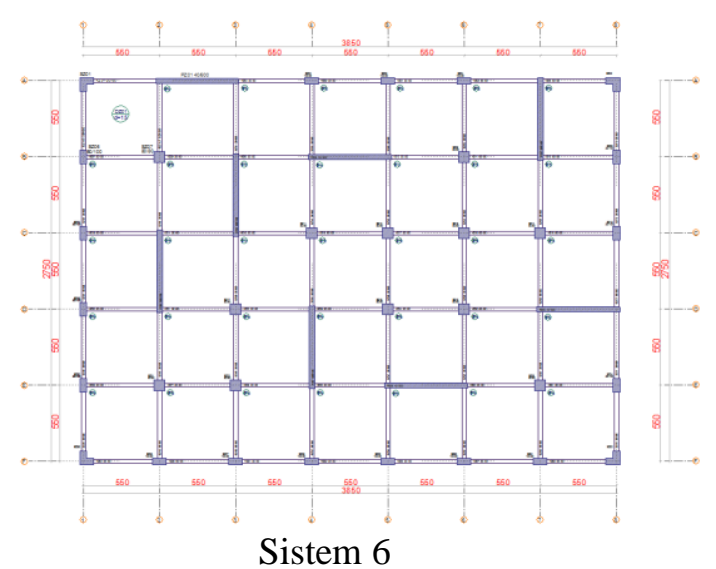




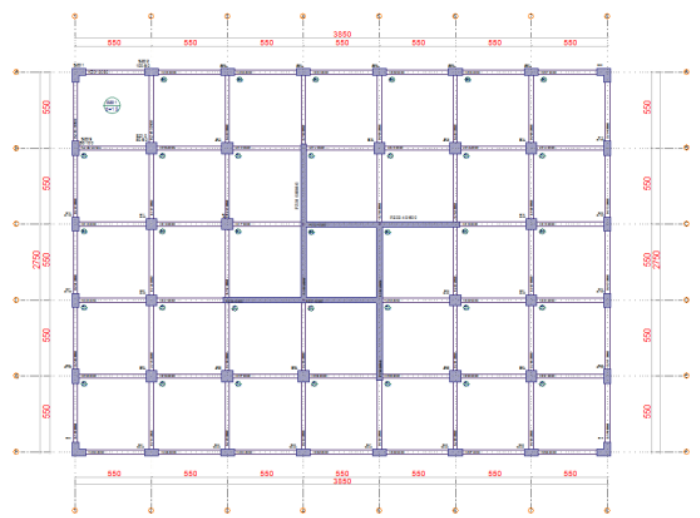

Sistem 7

Şekil 5. Analiz için hazırlanan 11 katlı betonarme yapıların perdeli-çerçeveli taşıyıcı sistem modelleri

Tüm modellerde C35 beton sınıfı ve B420C donatı çeliği kullanılmıştır. Planlanan yapı 11 katlı olup (39.00x28.00m) 1092,00 $\mathrm{m}^{2}$ kat alanına sahiptir.

Sistem 1, referans plan olarak belirlenen ve taşıyıcı sistemi çerçeve olan sistemdir. Perde elemanı içermemektedir.

Sistem 2 için düşey taşıyıcı olan kolonlara ek olarak, sadece $\boldsymbol{Y}$ doğrultusuna 8 adet 40x600cm ebatlarında simetrik olarak perdeler eklenmiştir.

Sistem 3 için düşey taşıyıcı olan kolonlara ek olarak, sadece $\boldsymbol{X}$ doğrultusuna 8 adet $40 \times 600 \mathrm{~cm}$ ebatlarında simetrik perdeler yerleştirilmiştir.

Sistem 4 için düşey taşıyıcı olan kolonlara ek olarak, 4 adet $X$ yönünde ve 4 adet $Y$ yönünde olmak üzere toplamda 8 adet 40x600 cm uzunluğunda perde eklenmiştir.

Sistem 5 için düşey taşıyıcı olan kolonlara ek olarak özellikle yapının burulmasını sınırlandırmak amacıyla 4 köşede ve dış çevrede toplam 8 adet $40 \times 600 \mathrm{~cm}$ uzunluğunda perdeler teşkil edilmiştir. Sistem 6 için düşey taşıyıcı olan kolonlara ek olarak 4 adet $X$ yönünde ve 4 adet $Y$ yönünde olmak üzere asimetrik olarak toplamda 8 adet $40 \times 600 \mathrm{~cm}$ uzunluğunda perde eklenmiştir.

Sistem 7 için düşey taşıyıcı olan kolonlara ek olarak 4 adet $X$ yönünde ve 4 adet $Y$ yönünde olmak üzere binanın çekirdek bölgesinde toplamda 8 adet 40x600cm uzunluğunda perde eklenmiştir.

\section{Analiz Sonuçlarının Değerlendirilmesi ve Karşılaştırılması}

Tüm sistemlerden elde edilen değerlerin birbirleriyle karşılaştırılması ile perde yeri değişiminin, taşıyıcı sistemin yapısal performansını nasıl etkilediği araştırılmıştır.

\subsection{Göreli Kat Ötelemesi}

Tüm sistemlerde göreli kat ötelemeleri tüm katlar için ayrı ayrı incelenmiş olup, her sistemde oluşan maksimum göreli kat ötelemeleri aşağıdaki Şekil 6’ da gösterilmiştir. 


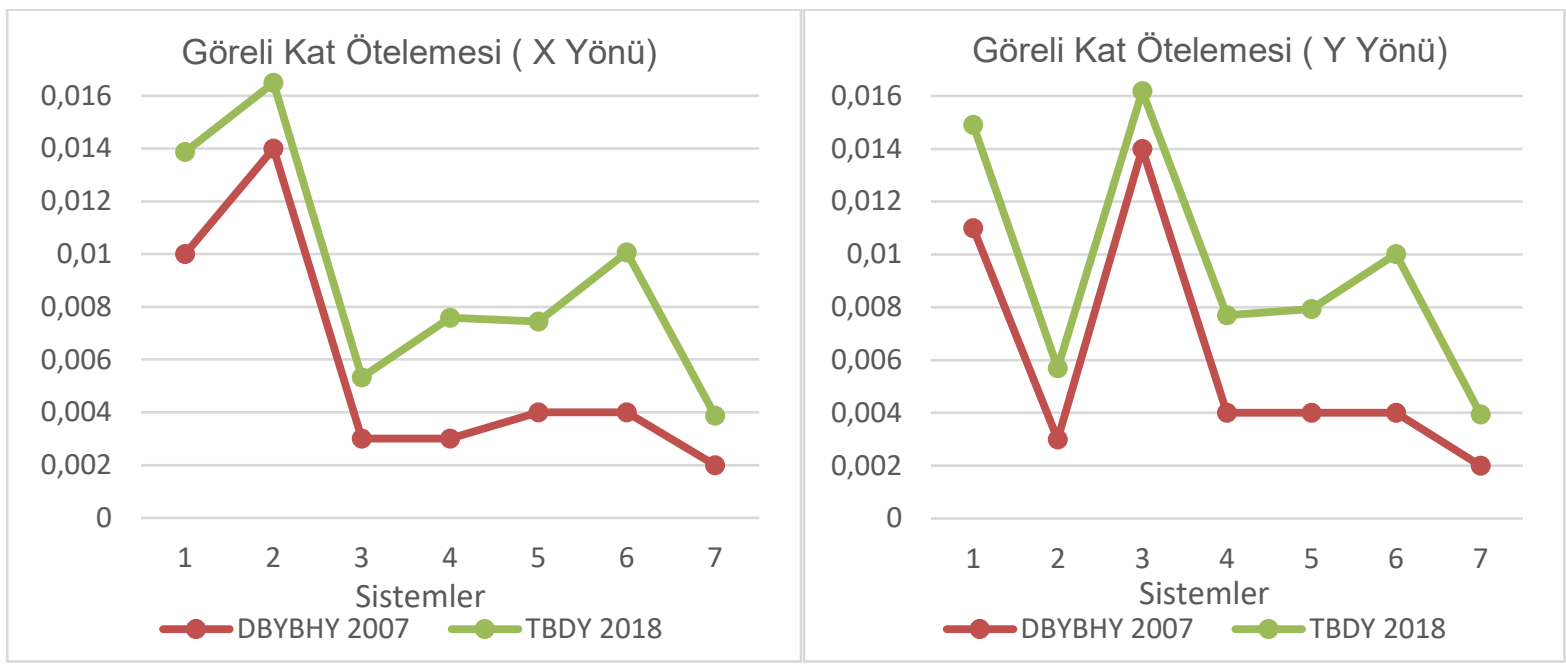

Şekil 6. 5 katlı yapı sistemlerinde göreli kat ötelemesi karşılaştırması

Çözümleme sonucu veriler incelediğinde TBDY 2018 sınır değeri, DBYBHY 2007'deki sınır değerinin 0.4 katıdır. Değerin bu kadar küçülmesi TBDY 2018' e göre analiz yapılan tüm sistemlerde göreli kat ötelemesi sınırının aşılamamasına neden olmuştur. DBYBHY 2007 göreli kat öteleme sınırını aşmamak için perdeler sistemlere her iki yönde ve düzenli bir şekilde yerleştirilmesi gerektiği görülmektedir. Bu da yapılan sistemlerin daha rijit olması gerektiğini göstermektedir. Sadece çerçeveli sistemlerle oluşan sistemlerde bu rijitliği sağlamak çok zordur. Grafiklerde de görüldüğü gibi sistemlere eşit miktarda perde eklemek sistemin rijitliğini etkilememektedir. Göreli kat öteleme sınırını aşmamak için perdeler sistemlere her iki yönde ve düzenli bir şekilde yerleştirilmelidir.

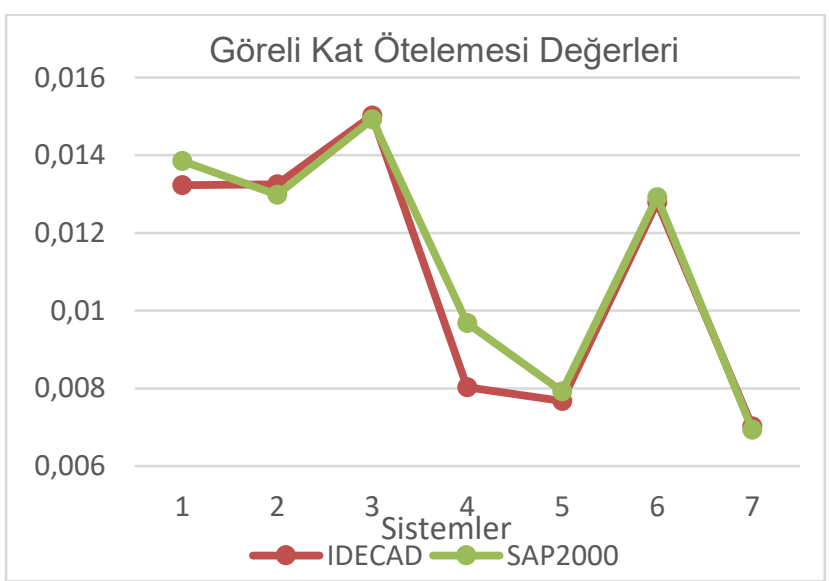

Şekil 7. 11 katlı yapı sistemlerinde göreli kat ötelemesi karşılaştırması

Çözümleme sonucu veriler incelediğinde Şekil 7' de görüldüğü gibi sistemlerde göreli kat ötelemesi sınırı aşılmamıştır. Yapısal çözümleme aşamasında kabul edilen, dolgu duvarlar ile taşıyıcı elemanların arasına esnek derzler yapılması çok önemlidir. Göreli kat ötelemenin en düşük olduğu sistem 7'dir. Perde alanlarının aynı olmasına rağmen sistemlerin birbirinden farklı kat ötelemesi yaptığı görülmektedir. Düşey taşıyıcı alanları neredeyse aynı olan sistemlerin, ağırlıklarının da birbirine yakın olduğu düşünülürse perdenin sisteme yerleşim düzeninin yarattığı farklılığı çok açık görülebilir. 


\subsection{Periyotların Karşılaştırılması}

Aynı kat alanına sahip sistemlerin, taşıyıcı sistemleri farklı olduğu için farklı rijitliklere sahip olduğundan, yapı modal analiz sonucu bulunan periyotlar da farklıdır. Sistemlerin T1, periyotları Şekil 8'de gösterilmiştir.

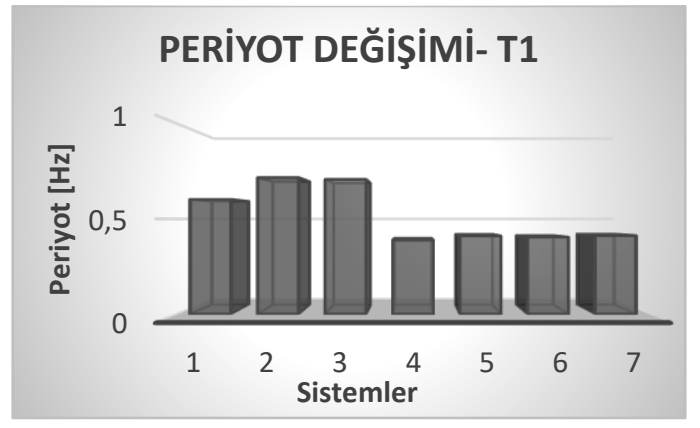

Şekil 8.a. 5 Katlı sistemlerin T1 periyotları

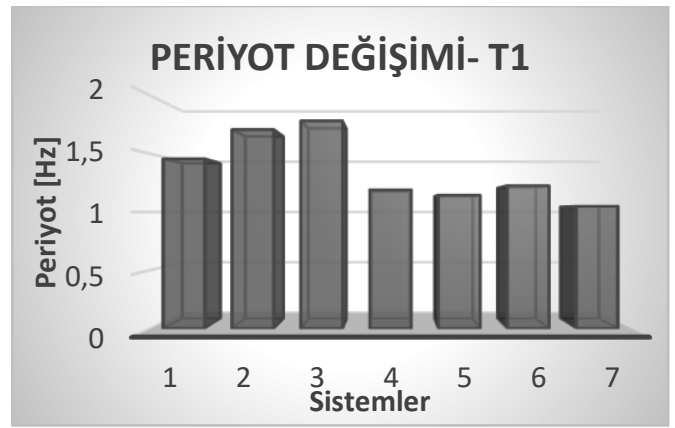

Şekil 8.b. 11 Katlı sistemlerin T1 periyotları

Burada görüldüğü üzere yapıdaki perde sayısının aynı olmasına rağmen, sistem periyotları birbirlerinden farklıdır. Düşey taşıyıcı alanı artıkça ötelenme rijitliği artacağı için sistemlerin periyotları düşecektir. Her iki yönde aynı miktarda yerleştirilen perdeli sistemlerdeki periyotlar birbirine yakın değerdedir. Tek bir yönde perde yerleştirilen sistemler çerçeveli sistemlere göre periyotları oldukça yüksektir. Periyotların bu şekilde ortaya çıkması, bu taşıyıcı sistem grupları için perde alanının sistemlerin periyotların da etkin olduğu fakat aynı perde alanına sahip olunsa bile perde yerinin sistem periyodunu etkilediği kanısına varılabilir.

\section{Sonuçlar ve Değerlendirmeler}

Bu çalışmasında kat yüksekliğinin değişken olduğu bir zeminde, yapılacak yapıların deprem kuvvetleri etkisi altında yapısal davranışları incelenmiştir. 1. derece deprem bölgesine konumlandırılmış, 5 katlı ve 11 katlı betonarme yapıların perde yerleşim düzeni değiştirilerek önerilen farklı sistemlerdeki göreli kat ötelemeleri ve yapı periyotları araştırılmıştır.

Yapısal çözümleme sonucunda 5 katlı sistemlerin DBYBHY 2007 yönetmeliğine göre göreli kat ötelemesi sınırı aşılmamıştır. Fakat TBDY 2018'de bu sınır değerinin azalmasından dolayı bazı sistemlerde göreli kat ötelemesi sınırı aşılmıştır. Özellikle çerçeveli, tek bir doğrultuda konulan perdeler ve asimetrik perde yerleşime sahip olan sistemlerde bu sınır aşılmıştır. Sisteme düzenli yerleştirilen, sadece köşe kenarlara ve ya yapının merkezine konulan perdelerle oluşturulan perdeli-çerçeveli sistemlerde göreli kat ötelemesi yönetmeliğin izin verdiği sınır değerlerine uygundur. TBDY 2018' de değişen hesap yöntemleri sonucunda sistemlerdeki katlara gelen kesme kuvvetleri ve periyot değerleri artmıştır.

Bu çalışmanın sonunda, sistemlerde çeşitli düzensizliklerin önlenmesi için rijittlik elemanları olan, kolon ve perde elemanlarının, yapıya her iki deprem doğrultusunda ve simetrik olarak yerleştirilmelidir. Yapılarda perdeler yatay rijitliği arttırarak rölatif kat yer değiştirmelerini sınırlandırmıştır ve perdelerin bulunduğu doğrultuda daha fazla kesme kuvveti etkidiği görülmüştür. Kat sayısı artan sistemlerde yapının rijitliğini arttıracak önlemler alınması gerekmektedir. Rijitliğin artmasıyla periyot değerlerini aşağı seviyelere çekecektir. Bunun sonucu olarak yapılarda beklenen yeterli rijitlik sağlanmış olacaktır. Tüm bu ifadeler doğrultusunda yapılarda bulunan perde alanının yanı sıra perde yerleşim düzeninin yapı davranışında etkin rol oynadığ1 görülmüştür. 


\section{Kaynaklar}

[1] Celep, Z., 2015, Deprem mühendisliğine giriş. İstanbul, Beta Dağıtım.

[2]. Celep, Z., 2015, Yapı dinamiği. İstanbul, Beta Dağıtım.

[3] 2018 Türkiye Bina Deprem Yönetmeliği, Ankara, Ocak, 2019

[4] TS498 "Yapı Elemanlarının Boyutlandırılmasında Alınacak Yüklerin Hesap Değerleri" Türk Standartları Enstitüsü, Ankara, 1997

[5] TS500, "Betonarme Yapıların Hesap ve Yapım Kuralları", Türk Standartları Enstitüsü, Ankara, 2000

[6] Doğangün, A., 2018, Betonarme yapıların hesap ve tasarımı. İstanbul, Birsen Yayınevi

[7] Özlü, B., 2015, Çok katlı betonarme binalarda taşıyıcı sistem türlerinin davranışlarının incelenmesi. Yüksek Lisans Tezi, İstanbul Teknik Üniversitesi Fen Bilimleri Enstitüsü.

[8] Yıldız, İ., 2015, Perdeli ve perdesiz betonarme yapıların TDY 2007'ye göre değerlendirilmesi. Yüksek Lisans Tezi: Aksaray Üniversitesi Fen Bilimleri Enstitüsü.

[9] Ghobarah, A. \& Yousef, M., 1999, Modelling of reinforced concrete structural walls. Engineering Structures, 21(10), pp. 912-923. 